\title{
Conformationally Constrained Analogues of Diacylglycerol. 24. Asymmetric Synthesis of a Chiral $(R)$ - DAG-Lactone Template as a Versatile Precursor for Highly Functionalized DAG-Lactones.
}

\author{
Ji-Hye Kang, ${ }^{\dagger}$ Maqbool A. Siddiqui, ${ }^{\dagger}$ Dina M. Sigano, ${ }^{\dagger}$ Krzysztof Krajewski, $^{\dagger}$ Nancy \\ E. Lewin, ${ }^{\ddagger}$ Yongmei Pu, ${ }^{\ddagger}$ Peter M. Blumberg, ${ }^{\ddagger}$ Jeewoo Lee ${ }^{\star \S}$ and Victor E. Marquez ${ }^{\star \dagger}$ \\ Laboratory of Medicinal Chemistry, Center for Cancer Research, National Cancer Institute - Frederick, \\ National Institutes of Health, Frederick, MD 21702; Laboratory of Cellular Carcinogenesis \& Tumor \\ Promotion, Center for Cancer Research, National Cancer Institute, National Institutes of Health, Bethesda, \\ MD 20892; and Laboratory of Medicinal Chemistry, College of Pharmacy, Seoul National University, \\ Shinlin Dong, Kwanak-ku, Seoul 151-742, South Korea
}

Laboratory of Medicinal Chemistry, National Institutes of Health

Laboratory of Cellular Carcinogenesis \& Tumor Promotion, National Institutes of Health

${ }^{\S}$ Laboratory of Medicinal Chemistry, Seoul National University 


\section{Supporting Information}

\section{Analysis of Inhibition of $\left[{ }^{3} \mathrm{H}\right] \mathrm{PDBU}$ Binding by Non-radioactive Ligands. Enzyme-} ligand interactions were analyzed by competition with $\left[{ }^{3} \mathrm{H}\right] \mathrm{PDBU}$ binding for the single isozyme PK-C $\alpha$ essentially as described previously. ${ }^{1}$ The $\mathrm{ID}_{50}$ values were determined by least square fitting of the theoretical sigmoidal competition curve to the binding data. The $K_{\mathrm{i}}$ was calculated from the $\mathrm{ID}_{50}$ values according to the relationship

$$
\mathrm{K}_{\mathrm{i}}=\mathrm{ID}_{50} /\left(1+L / \mathrm{K}_{\mathrm{d}}\right)
$$

where $L$ is the concentration of free $\left[{ }^{3} \mathrm{H}\right] \mathrm{PDBU}$ at the $\mathrm{ID}_{50}$ and $K_{\mathrm{d}}$ is the dissociation constant for $\left[{ }^{3} \mathrm{H}\right] \mathrm{PDBU}$ under the assay conditions. ${ }^{1}$ Values represent the mean \pm standard error (three determinations). The octanol/water partition coefficients (log P) were calculated according to the fragment-based program KOWWIN 1.67 (http://www.epa.gov/oppt/exposure/docs/episuitedl.htm).

\section{Determination of Optical Purity.}

Chiral HPLC. Using a ChiraCel OD column, racemic and optically pure samples of (E)10 and $(\mathrm{Z})-10$ were analyzed under the following conditions:

Column: ChiraCel OD 250 x $10 \mathrm{~mm}$

Solvent: Isocratic conditions, hexanes:isopropanol (120:1)

Flow: $4 \mathrm{~mL} / \mathrm{min}$

Detection wavelength: $220 \mathrm{~nm}$

Chart speed: $1 \mathrm{~mm} / \mathrm{min}$ 
${ }^{1}$ H NMR spectra in the presence of europiumtris[3-trifluoromethylhydroxymethylene)(+)-camphorate].

All samples were dissolved in $\mathrm{CDCl}_{3}$ in a 2:1 (w/w) ratio of DAG-lactone to Eu shift reagent.

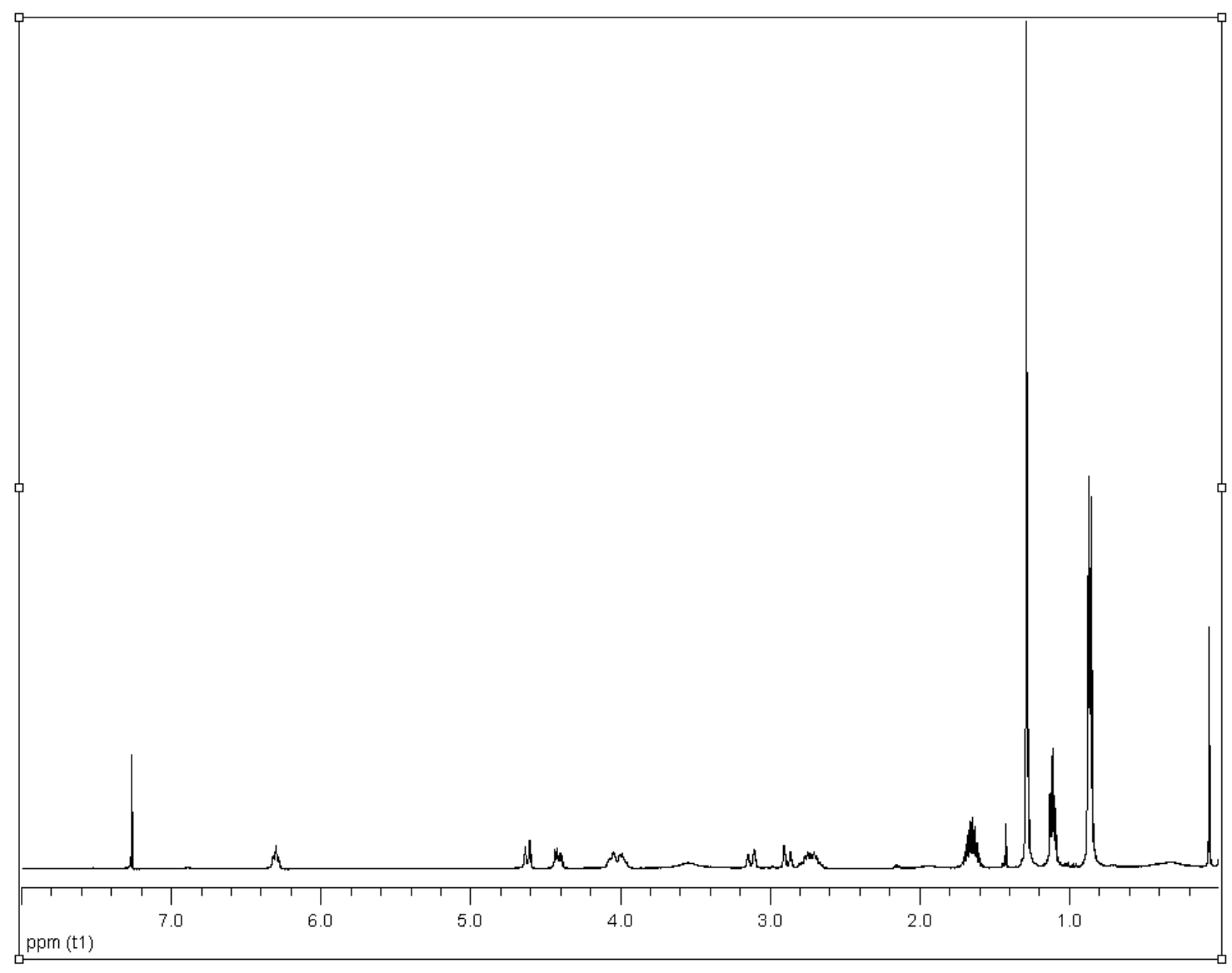

Figure 1. Full ${ }^{1} \mathrm{H}$ NMR spectrum of $r a c-(Z)-\mathbf{1 0}$ in the presence of Eu shift reagent. 


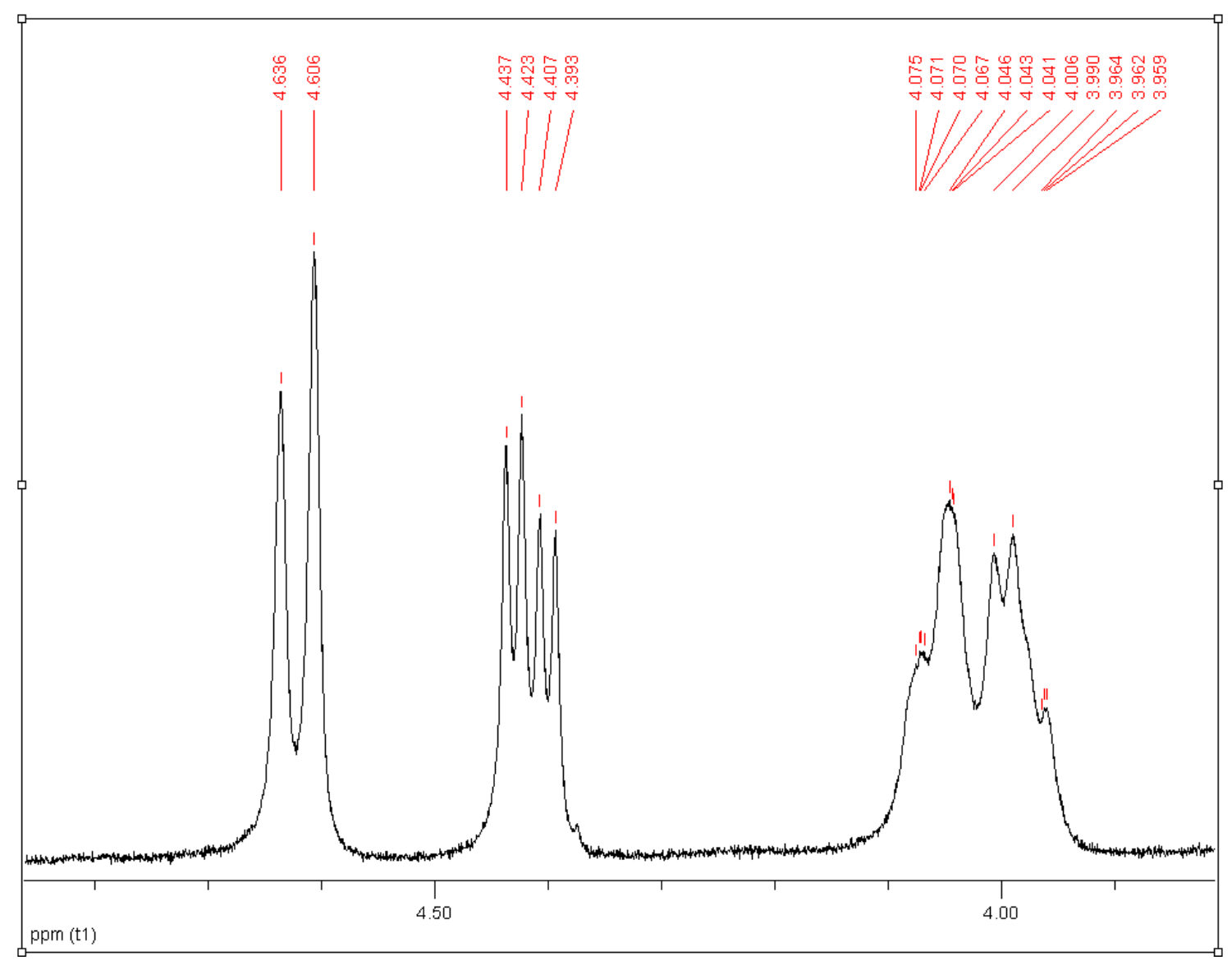

Figure 2. Expanded area of interest in Figure 1. 


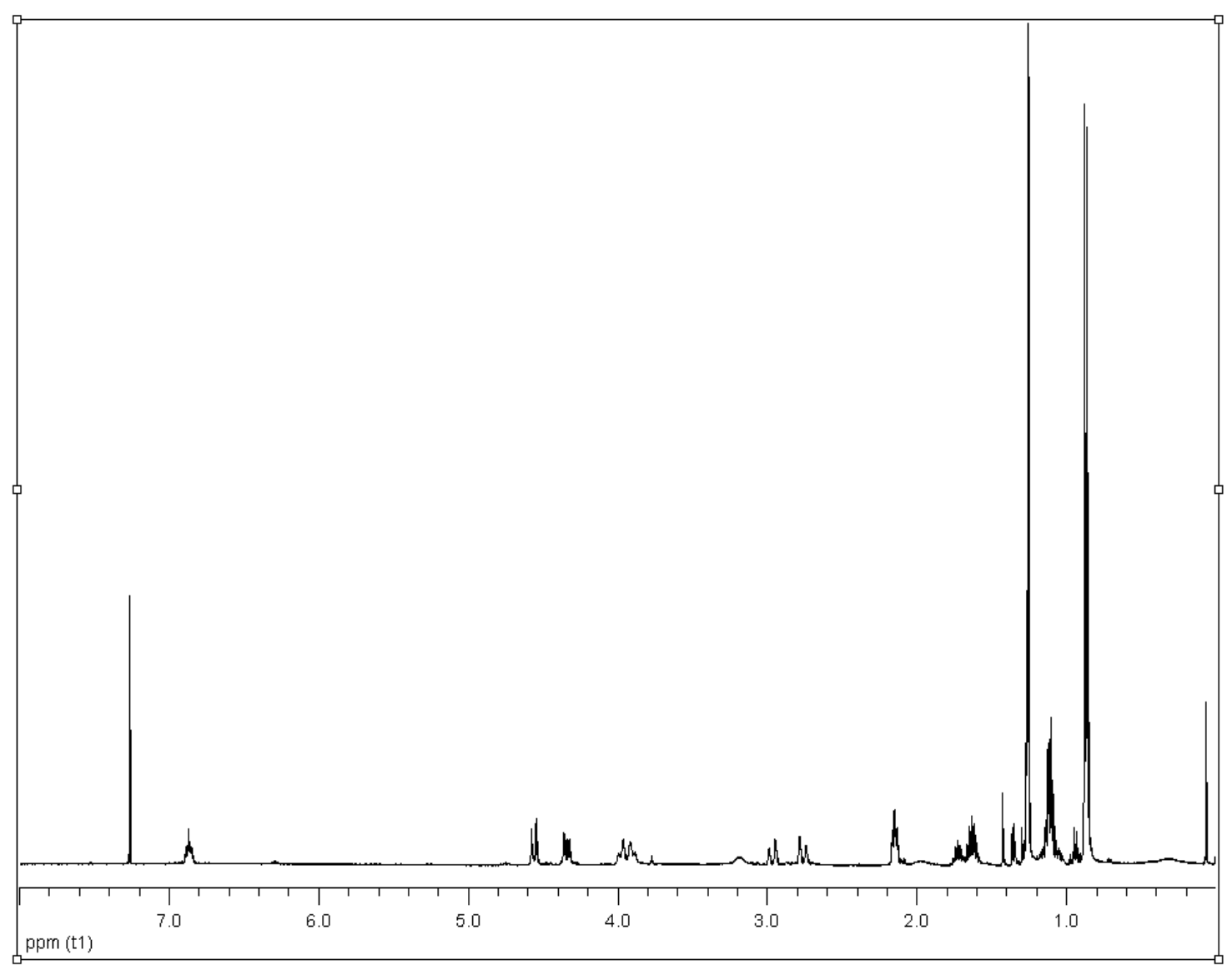

Figure 3. Full ${ }^{1} \mathrm{H}$ NMR spectrum of $r a c-(E)-\mathbf{1 0}$ in the presence of Eu shift reagent. 


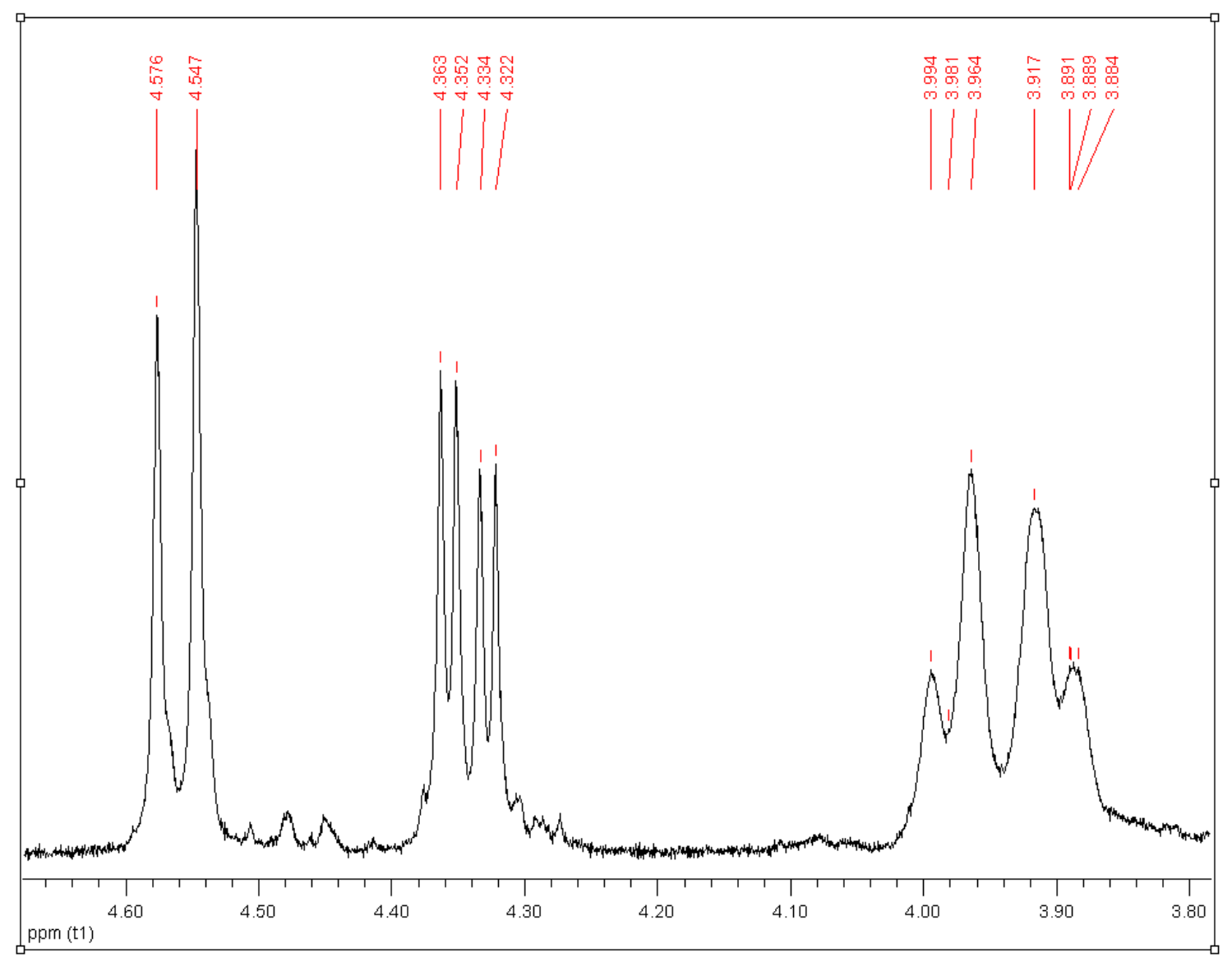

Figure 4. Expanded area of interest in Figure 3. 


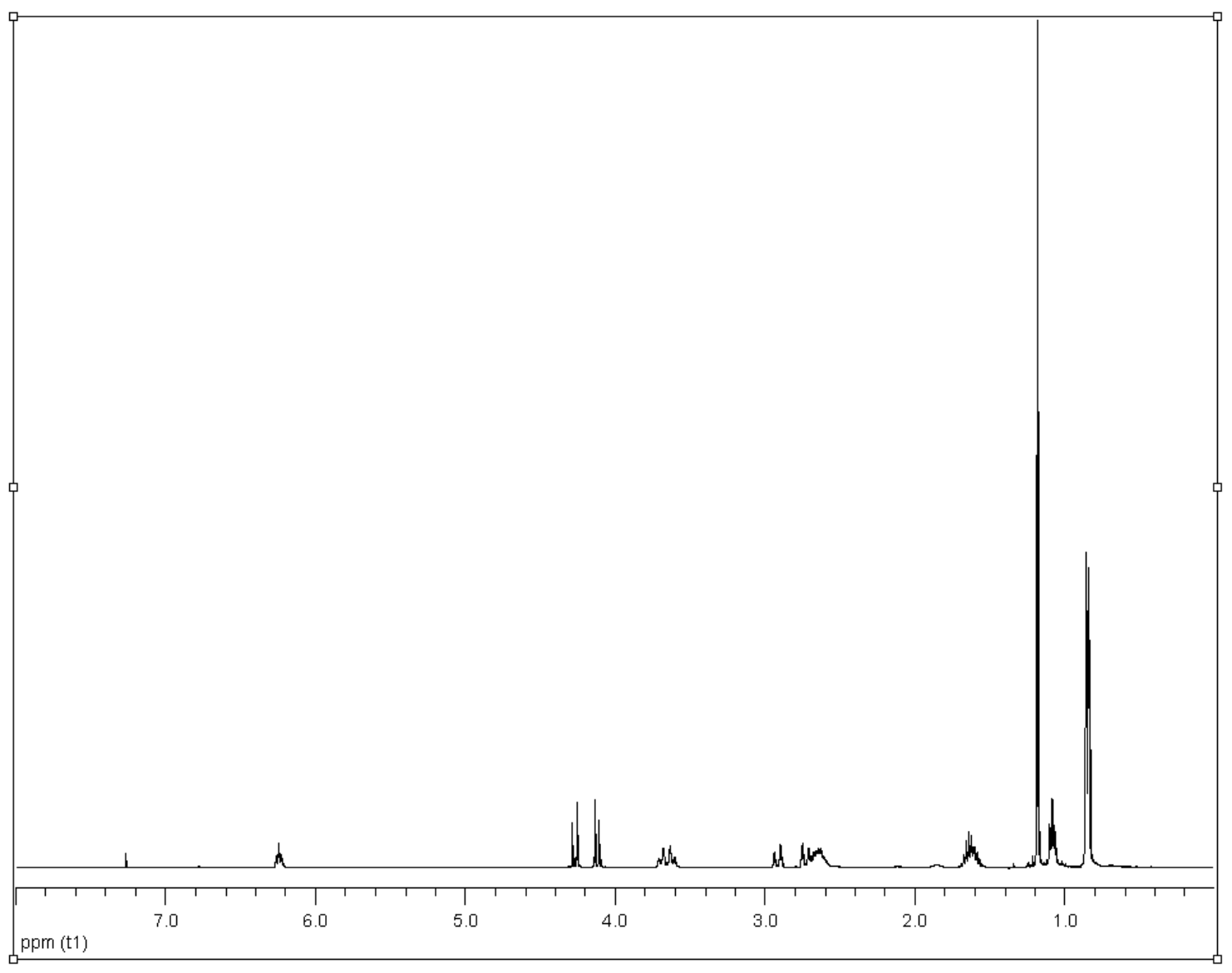

Figure 5. Full ${ }^{1} \mathrm{H}$ NMR spectrum of optically pure (Z)-10 without Eu shift reagent. 


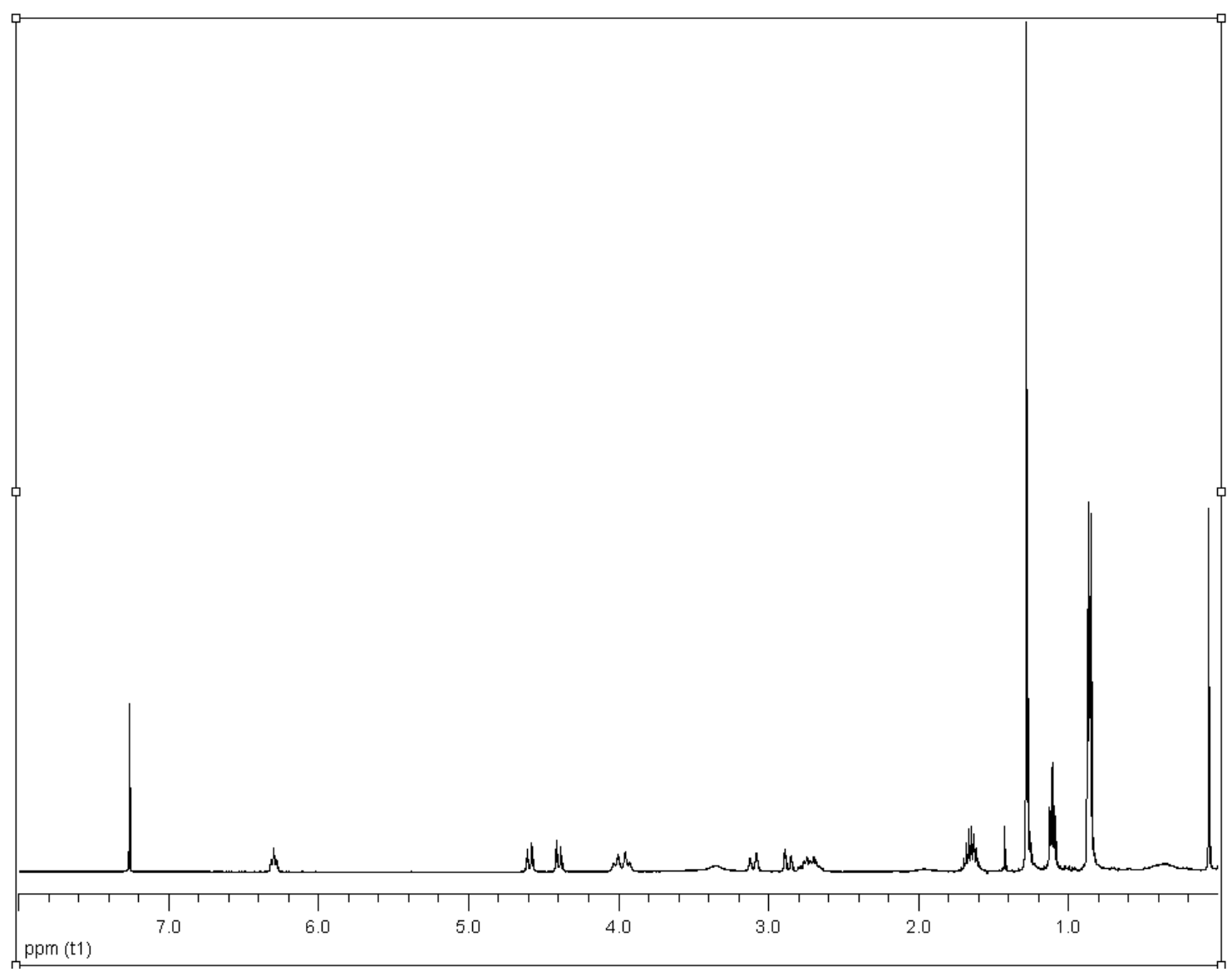

Figure 6. Full ${ }^{1} \mathrm{H}$ NMR spectrum of optically pure (Z)-10 with Eu shift reagent. 


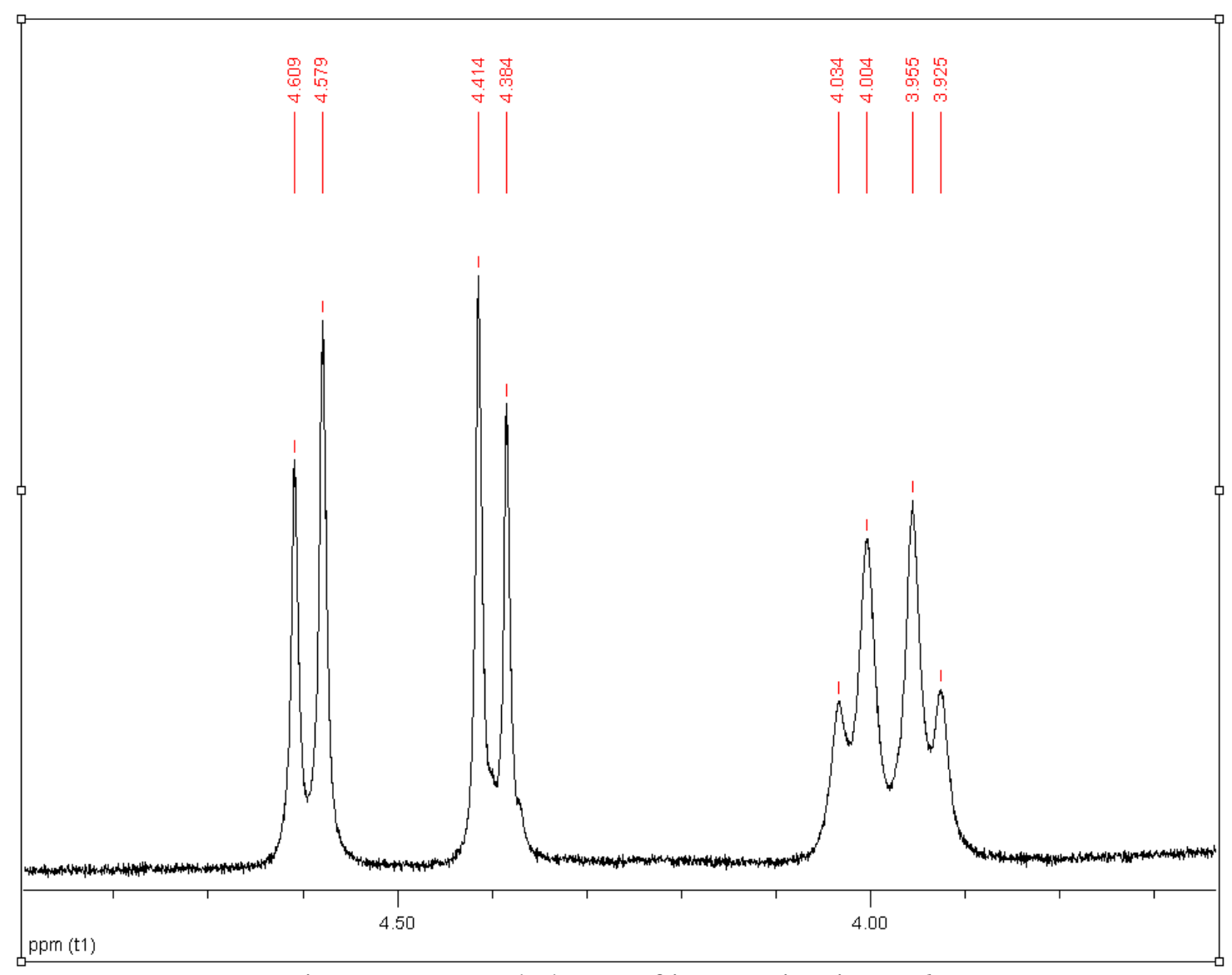

Figure 7. Expanded area of interest in Figure 6. 


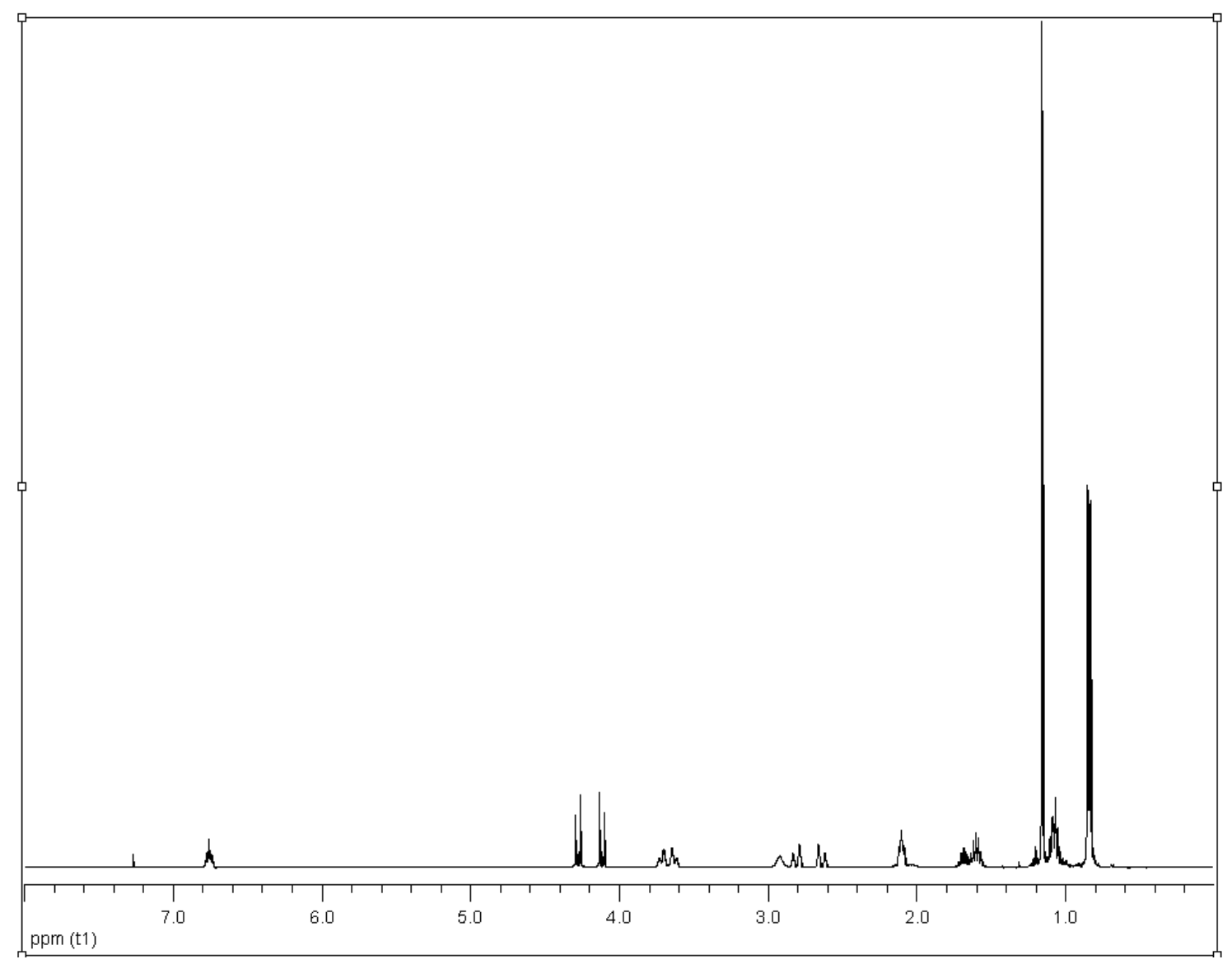

Figure 8. Full ${ }^{1} \mathrm{H}$ NMR spectrum of optically pure $(E)-\mathbf{1 0}$ without Eu shift reagent. 


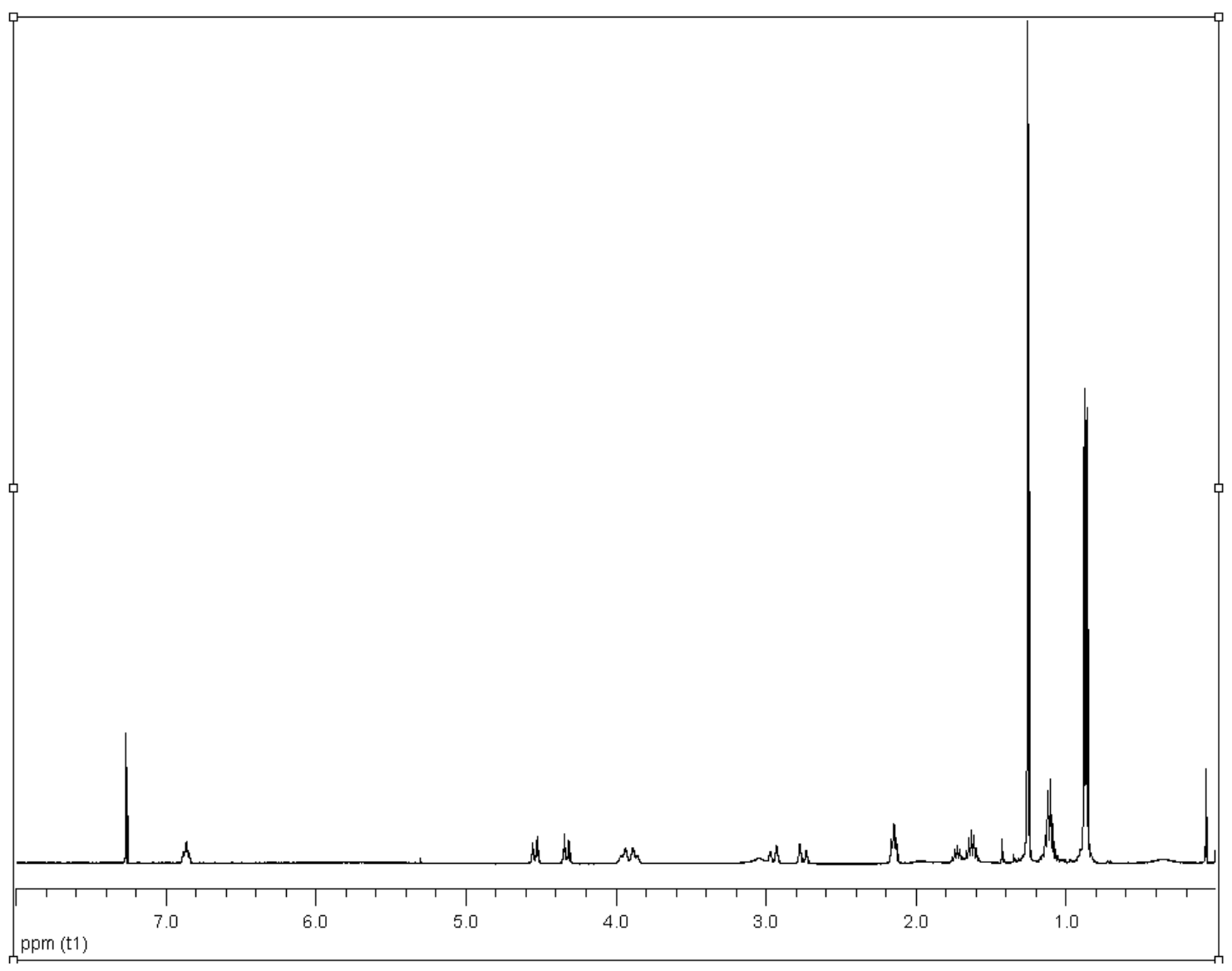

Figure 9. Full ${ }^{1} \mathrm{H}$ NMR spectrum of optically pure $(E)-\mathbf{1 0}$ with Eu shift reagent. 


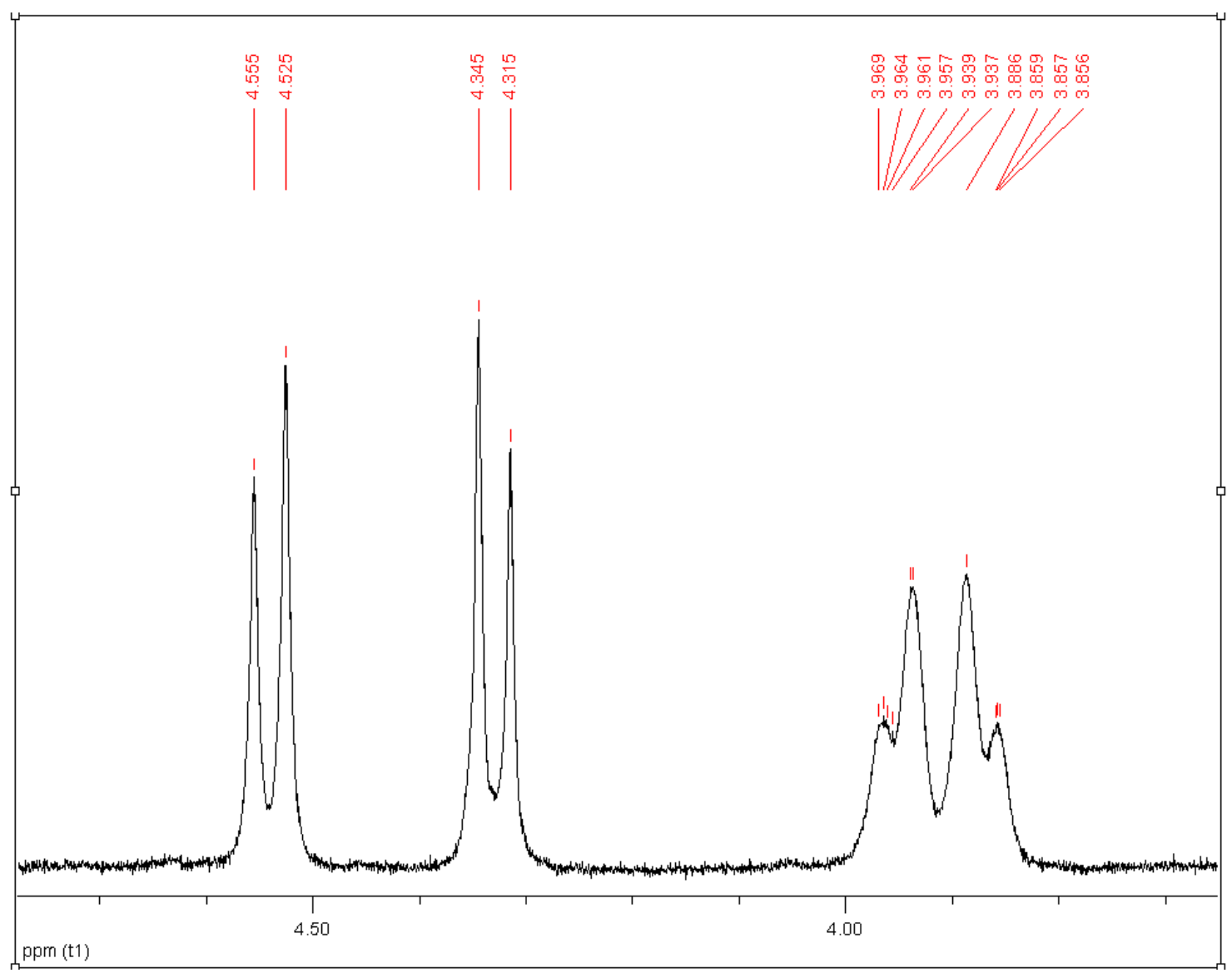

Figure 10. Expanded area of interest in Figure 9. 
General Procedures. All chemical reagents were commercially available. Column chromatography was performed on silica gel 60, 230-400 mesh (E. Merck). ${ }^{1} \mathrm{H}$ and ${ }^{13} \mathrm{C}$ NMR spectra were recorded on a Varian Unity Inova instrument at 400 and $100 \mathrm{MHz}$, respectively. Spectra are referenced to the solvent in which they were run (7.24 ppm for $\mathrm{CDCl}_{3}$ ). Infrared spectra were recorded on a Jasco model 615 FT-IR instrument. Positive-ion, fast-atom bombardment mass spectra (FAB-MS) were obtained on a VG 7070E-HF double-focusing mass spectrometer operated at an accelerating voltage of 6 $\mathrm{kV}$ under the control of a MASPEC-II ${ }^{32}$ data system for Windows (Mass Spectrometry Services, Ltd.). Either glycerol or 3-nitrobenzyl alcohol was used as the sample matrix, and ionization was effected by a beam of xenon atoms generated in a saddle-field ion gun at $8.0 \pm 0.5 \mathrm{kV}$. Nominal mass spectra were obtained at a resolution of 1200 , and matrixderived ions were background subtracted during data system processing. Optical rotations were recorded on a Jasco P-1010 polarimeter. Elemental analyses were performed by Atlantic Microlab, Inc., Atlanta, GA.

\section{2-[(Triphenylmethoxy)methyl]prop-2-en-1-ol (1)}

A solution of commercially available 2-methylenepropane-1,3-diol (2.0 g, $23 \mathrm{mmol})$ in $\mathrm{CH}_{2} \mathrm{Cl}_{2}(10 \mathrm{~mL})$ was reacted with trityl chloride $(6.3 \mathrm{~g}, 23 \mathrm{mmol})$ in the presence of $\mathrm{Et}_{3} \mathrm{~N}$ $(6.4 \mathrm{~mL}, 46 \mathrm{mmol})$ and stirred for $1 \mathrm{~h}$ at room temperature. The reaction mixture was diluted with $\mathrm{H}_{2} \mathrm{O}(21 \mathrm{~mL})$ and extracted with EtOAc $(3 \times 30 \mathrm{~mL})$. The combined organic layers were washed with brine, dried $\left(\mathrm{MgSO}_{4}\right)$ and concentrated in vacuo. The residue was purified by flash column chromatography on silica gel with EtOAc:hexanes (1:10) as eluant to give $1(4.1 \mathrm{~g}, 52 \%)$ as a solid. $\mathrm{mp} 80-81{ }^{\circ} \mathrm{C} ;{ }^{1} \mathrm{H} \mathrm{NMR}\left(\mathrm{CDCl}_{3}\right) \delta$ 7.43-7.47 (m, 6 
$\left.\mathrm{H}, \mathrm{CH}_{2} \mathrm{OCPh}_{3}\right), 7.22-7.34\left(\mathrm{~m}, 9 \mathrm{H}, \mathrm{CH}_{2} \mathrm{OCPh}_{3}\right), 5.23(\mathrm{~d}, 1 \mathrm{H}, J=1.4 \mathrm{~Hz},>\mathrm{C}=\mathrm{C} \underline{H H})$, $5.17(\mathrm{~d}, 1 \mathrm{H}, J=1.6 \mathrm{~Hz},>\mathrm{C}=\mathrm{CH} \underline{\mathrm{H}}), 4.14\left(\mathrm{~d}, 2 \mathrm{H}, J=6.1 \mathrm{~Hz}, \mathrm{CH}_{2} \mathrm{OH}\right), 3.70(\mathrm{~s}, 2 \mathrm{H}$, $\mathrm{C}_{2} \mathrm{OCPh}_{3}$ ), 1.67 (t, $1 \mathrm{H}, J=6.2 \mathrm{~Hz}, \mathrm{CH}_{2} \mathrm{O} \underline{\mathrm{H}}$ ); FABMS $\mathrm{m} / z$ (relative intensity) 369 ( $\left.\mathrm{MK}^{+}, 16\right), 330\left(\mathrm{M}^{+\bullet}, 1\right) 243$ (100). Anal. Calcd for $\mathrm{C}_{23} \mathrm{H}_{22} \mathrm{O}_{2}: \mathrm{C}, 83.52 ; \mathrm{H}, 6.67$. Found: C, 83.60; H, 6.67.

(R)-\{2-[(Triphenylmethoxy)methyl]oxiran-2-yl\}methan-1-ol (2). An oven dried round bottom flask equipped with a magnetic stir bar and a nitrogen inlet was charged with activated $4 \AA$ powdered molecular sieves ( $3 \mathrm{~g}$ ) and dry $\mathrm{CH}_{2} \mathrm{Cl}_{2}(5 \mathrm{~mL})$. The flask was then cooled to $-20^{\circ} \mathrm{C}$ and L-(+)-diethyl tartrate $(21 \mu \mathrm{L}, 0.124 \mathrm{mmol})$ and $\mathrm{Ti}\left[\mathrm{OCH}\left(\mathrm{CH}_{3}\right)_{2}\right]_{4}(0.18 \mathrm{ml}, 0.62 \mathrm{mmol})$ were added sequentially and stirred for $40 \mathrm{~min}$. While still at $-20^{\circ} \mathrm{C}, t-\mathrm{BuOOH}(5.0 \mathrm{M}$ in nonane, $2.5 \mathrm{~mL}, 12.5 \mathrm{mmol})$ was added and the reaction mixture was stirred for an additional $40 \mathrm{~min}$. A solution of alkene 1 (2.04 g, 6.2 mmol), dissolved in $\mathrm{CH}_{2} \mathrm{Cl}_{2}(5 \mathrm{~mL})$, was then added and stirring was continued for $8 \mathrm{~h}$ at $-20^{\circ} \mathrm{C}$. The reaction mixture was then warmed to $0{ }^{\circ} \mathrm{C}$, diluted with $\mathrm{H}_{2} \mathrm{O}(3.6 \mathrm{~mL}$, ca. 20 equiv $\mathrm{w} / \mathrm{w} t-\mathrm{BuOOH}$ ) and stirred for $30 \mathrm{~min}$, while warming to room temperature. The tartrate was then hydrolyzed with a $30 \% \mathrm{NaOH}$ solution saturated with sodium chloride under vigorous stirring. After $1 \mathrm{~h}$, the reaction mixture was diluted with $\mathrm{H}_{2} \mathrm{O}(21 \mathrm{~mL})$ and extracted with $\mathrm{CH}_{2} \mathrm{Cl}_{2}$. The combined organic layer was washed with brine, dried $\left(\mathrm{MgSO}_{4}\right)$, and concentrated in vacuo. The residue was purified by flash column chromatography on silica gel with EtOAc:hexanes (1:10) as eluant to give 2 (1.73 g, $80 \%$, ee $>96 \%)$ as a white solid; $\mathrm{mp} 119-120{ }^{\circ} \mathrm{C} ;[\alpha]_{\mathrm{D}}{ }^{22}=-19.5\left(c 1.5, \mathrm{CHCl}_{3}\right) ;{ }^{1} \mathrm{H}$ $\operatorname{NMR}\left(\mathrm{CDCl}_{3}\right) \delta$ 7.41-7.48 (m, $\left.6 \mathrm{H}, \mathrm{CH}_{2} \mathrm{OCPh}_{3}\right), 7.22-7.35\left(\mathrm{~m}, 9 \mathrm{H}, \mathrm{CH}_{2} \mathrm{OCPh}_{3}\right), 3.92$ 
(dd, $1 \mathrm{H}, J=12.3,4.7 \mathrm{~Hz}, \mathrm{C} \underline{\mathrm{HHOH}}), 3.76$ (dd, $1 \mathrm{H}, J=12.3,8.4 \mathrm{~Hz}, \mathrm{CH} \underline{\mathrm{HOH}}$ ), 3.30 (AB q, $\left.2 \mathrm{H}, J=10.5 \mathrm{~Hz}, \mathrm{C}_{2} \mathrm{OCPh}_{3}\right), 2.89$ (d, $\left.1 \mathrm{H}, J=4.9, \mathrm{~Hz}, \mathrm{C} \underline{H H O}\right), 2.81$ (d, $1 \mathrm{H}, J=4.8$, $\mathrm{Hz}, \mathrm{CH} \underline{\mathrm{HO}}$ ), 1.71 (dd, $1 \mathrm{H}, J=8.4,4.8 \mathrm{~Hz}, \mathrm{CH}_{2} \underline{\mathrm{OH}}$ ); FABMS m/z (relative intensity) 385 $\left(\mathrm{MK}^{+}, 45\right), 346\left(\mathrm{M}^{+\bullet}, 2\right), 243(100)$. Anal. Calcd for $\mathrm{C}_{23} \mathrm{H}_{22} \mathrm{O}_{3} \cdot 0.33 \mathrm{H}_{2} \mathrm{O}: \mathrm{C}, 78.39 ; \mathrm{H}$, 6.48. Found: C, 78.28; H, 6.39 .

\section{Preparation of the Mosher ester of $(R)-2$}

A stirred solution of epoxide $(R)-2(54 \mathrm{mg}, 0.155 \mathrm{mmol})$ in dry $\mathrm{CH}_{2} \mathrm{Cl}_{2}(2 \mathrm{~mL})$ was treated with $\mathrm{Et}_{3} \mathrm{~N}(120 \mu \mathrm{L}, 0.86 \mathrm{mmol})$ and DMAP $(19 \mathrm{mg}, 0.155 \mathrm{mmol})$ before the addition of $(R)-(+)-\alpha$-methoxy- $\alpha$-(trifluoromethyl)phenylacetic acid [(+)-MTPA, $32 \mu \mathrm{L}$, $0.171 \mathrm{mmol}]$. After $15 \mathrm{~min}$, the reaction was quenched by the addition of 3(dimethylamino)propylamine $(50 \mu \mathrm{L})$ and the entire mixture was loaded on a silical gel column and eluted with EtOAc:hexanes $(1: 20) \rightarrow(1: 2)$ as eluant to give the corresponding Mosher ester (84.6 mg, 96.5\%) as an oil; ${ }^{1} \mathrm{H}$ NMR $\left(\mathrm{CDCl}_{3}\right) \delta$ 7.20-7.45

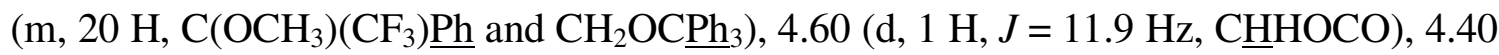
$(\mathrm{d}, 1 \mathrm{H}, J=11.9 \mathrm{~Hz}, \mathrm{CH} \underline{\mathrm{HOCO}}), 3.40\left(\mathrm{~s}, 3 \mathrm{H}, \mathrm{C}\left(\mathrm{OCH}_{3}\right)\left(\mathrm{CF}_{3}\right) \mathrm{Ph}\right), 3.14(\mathrm{AB} \mathrm{q}, 2 \mathrm{H}, J=$

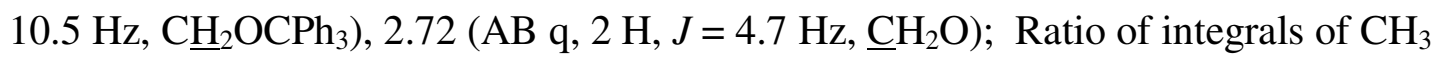
singlets at $\delta 3.40(3.0)$ and $\delta 3.48(0.1)$ corresponds to $>96 \%$ ee.

\section{(R)-4-\{2-[(Phenylmethoxy)methyl]oxiran-2-yl\}(triphenylmethoxy)methane (3). A}

solution of $(R)-2(1.7 \mathrm{~g}, 5.0 \mathrm{mmol})$ in DMF $(4 \mathrm{~mL})$ was treated with $\mathrm{NaH}(60 \%$ dispersion in mineral oil, $600 \mathrm{mg}, 15 \mathrm{mmol})$ and benzyl bromide $(0.89 \mathrm{~mL}, 7.5 \mathrm{mmol})$, and stirred for $1 \mathrm{~h}$ at room temperature. The reaction mixture was then diluted with $\mathrm{H}_{2} \mathrm{O}$ 
$(20 \mathrm{~mL})$ and extracted with EtOAc $(3 \times 30 \mathrm{~mL})$. The combined organic layers were washed with brine, dried $\left(\mathrm{MgSO}_{4}\right)$ and concentrated in vacuo. The residue was purified by flash column chromatography on silica gel with EtOAc:hexanes (1:10) as eluant to give $(R)-3(1.86 \mathrm{~g}, 86 \%)$ as an oil. $[\alpha]_{\mathrm{D}}{ }^{23}=-6.53\left(c 1.86, \mathrm{CHCl}_{3}\right) ;{ }^{1} \mathrm{H} \mathrm{NMR}\left(\mathrm{CDCl}_{3}\right) \delta$ 7.35-7.40 (m, $6 \mathrm{H}, \mathrm{CH}_{2} \mathrm{OCH}_{2} \mathrm{Ph}$ and $\left.\mathrm{CH}_{2} \mathrm{OCPh}_{3}\right), 7.12-7.25\left(\mathrm{~m}, 14 \mathrm{H}, \mathrm{CH}_{2} \mathrm{OCPh}_{3}\right), 4.45$ $\left(\mathrm{AB} \mathrm{q}, 2 \mathrm{H}, J=12.0 \mathrm{~Hz}, \mathrm{CH}_{2} \mathrm{OC} \underline{H}_{2} \mathrm{Ph}\right), 3.66\left(\mathrm{AB} \mathrm{q}, 2 \mathrm{H}, J=11.0 \mathrm{~Hz}, \mathrm{C}_{2} \mathrm{OCH}_{2} \mathrm{Ph}\right)$, $3.22\left(\mathrm{AB} \mathrm{q}, 2 \mathrm{H}, J=10.2, \mathrm{~Hz}, \underline{\mathrm{C}}_{2} \mathrm{OCPh}_{3}\right.$ ), 2.69 (AB q, $2 \mathrm{H}, J=5.0, \underline{\mathrm{C}}_{2} \mathrm{O}$ ); FABMS m/z (relative intensity) $475\left(\mathrm{MK}^{+}, 16\right), 437\left(\mathrm{MH}^{+}, 12\right), 243$ (100). Anal. Calcd for $\mathrm{C}_{30} \mathrm{H}_{28} \mathrm{O}_{3} \cdot 0.33 \mathrm{H}_{2} \mathrm{O}: \mathrm{C}, 81.43 ; \mathrm{H}, 6.52$. Found: $\mathrm{C}, 81.36 ; \mathrm{H}, 6.37$.

\section{(R)-2-[(Phenylmethoxy)methyl]-1-(triphenylmethoxy)pent-4-yn-2-ol (4).}

A solution of $(R)-3(1.86 \mathrm{~g}, 4.3 \mathrm{mmol})$ in DMSO $(8 \mathrm{~mL})$ was treated with lithium acetylide, ethylenediamine complex (920 $\mathrm{mg}, 10 \mathrm{mmol})$ and stirred for $2 \mathrm{~h}$ at room temperature. The reaction mixture was diluted with $\mathrm{H}_{2} \mathrm{O}(21 \mathrm{~mL})$ and extracted with EtOAc $(3 \times 30 \mathrm{~mL})$, and the combined organic layers were washed with brine, dried $\left(\mathrm{MgSO}_{4}\right)$ and concentrated in vacuo. The residue was purified by flash column chromatography on silica gel with EtOAc: hexanes $(1: 10)$ as eluant to give $4(1.552 \mathrm{~g}$, $79 \%)$ as an oil. $[\alpha]_{\mathrm{D}}{ }^{22}=-6.56\left(c 1.76, \mathrm{CHCl}_{3}\right) ;{ }^{1} \mathrm{H} \mathrm{NMR}\left(\mathrm{CDCl}_{3}\right) \delta 7.38-7.40(\mathrm{~m}, 5 \mathrm{H}$,

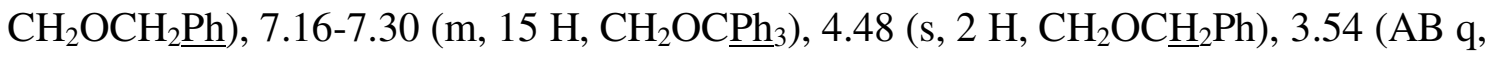
$2 \mathrm{H}, J=9.1 \mathrm{~Hz}, \mathrm{CH}_{2} \mathrm{OCH}_{2} \mathrm{Ph}$ ), 3.18 (irr AB q, $\left.2 \mathrm{H}, \underline{\mathrm{CH}}_{2} \mathrm{OCPh}_{3}\right), 2.44-2.56(\mathrm{~m}, 2 \mathrm{H}$, $\mathrm{C}_{2} \mathrm{C} \equiv \mathrm{CH}$ ) 1.86 (irr t, $1 \mathrm{H}, J=2.6 \mathrm{~Hz}, \mathrm{CH}_{2} \mathrm{C} \equiv \mathrm{CH}$ ); FABMS m/z (relative intensity) 501 $\left(\mathrm{MK}^{+}, 6\right), 463\left(\mathrm{MH}^{+}, 2\right), 243$ (100). Anal. Calcd for $\mathrm{C}_{32} \mathrm{H}_{30} \mathrm{O}_{3}: \mathrm{C}, 83.08 ; \mathrm{H}, 6.54$. Found: C, 83.04; H, 6.83 . 


\section{(R)-2-[(Phenylmethoxy)methyl]-1-(triphenylmethoxy)pent-4-en-2-ol (5).}

A suspension of $(R)-4(1.55 \mathrm{~g}, 3.4 \mathrm{mmol})$, Lindlar catalyst $(750 \mathrm{mg})$ and quinoline $(750$

$\mathrm{mg})$ in hexane $(10 \mathrm{~mL})$ was hydrogenated under a balloon-filled hydrogen atmosphere for $2 \mathrm{~h}$. The mixture was filtered, the filtrate was concentrated in vacuo and the residue was purified by flash column chromatography on silica gel with EtOAc as eluant to give $(R)-5$ as an oil $(1.52 \mathrm{~g}, 97 \%) .[\alpha]_{\mathrm{D}}{ }^{23}=-2.86\left(c 1.55, \mathrm{CHCl}_{3}\right) ;{ }^{1} \mathrm{H} \mathrm{NMR}\left(\mathrm{CDCl}_{3}\right) \delta 7.38-7.40(\mathrm{~m}$, $\left.5 \mathrm{H}, \mathrm{CH}_{2} \mathrm{OCH}_{2} \underline{\mathrm{Ph}}\right), 7.16-7.30\left(\mathrm{~m}, 15 \mathrm{H}, \mathrm{CH}_{2} \mathrm{OCPh}_{3}\right), 5.58-5.69\left(\mathrm{~m}, 1 \mathrm{H}, \mathrm{CH}_{2} \mathrm{C} \underline{\mathrm{H}}=\mathrm{CH}_{2}\right)$, 4.90-4.98 (m, $\left.2 \mathrm{H}, \mathrm{CH}_{2} \mathrm{CH}=\underline{\mathrm{CH}}_{2}\right), 4.47$ (s, $\left.2 \mathrm{H}, \mathrm{CH}_{2} \mathrm{OC}_{2} \mathrm{Ph}\right), 3.47$ (AB q, $2 \mathrm{H}, J=9.0$ $\mathrm{Hz}, \underline{\mathrm{C}}_{2} \mathrm{OCH}_{2} \mathrm{Ph}$ ), 3.06 (irr AB q, $2 \mathrm{H}, \underline{\mathrm{CH}}_{2} \mathrm{OCPh}_{3}$ ), 2.38 (s, $\left.1 \mathrm{H}, \mathrm{OH}\right), 2.28$ (d, $2 \mathrm{H}, J=$ 7.2 Hz, $\underline{\mathrm{CH}}_{2} \mathrm{CH}=\mathrm{CH}_{2}$ ); FABMS $m / z$ (relative intensity) $503\left(\mathrm{MK}^{+}, 4\right), 243$ (100). Anal. Calcd for $\mathrm{C}_{32} \mathrm{H}_{32} \mathrm{O}_{3} \cdot 0.25 \mathrm{H}_{2} \mathrm{O}$ : C, 81.93; H, 6.98. Found: C, 82.04; H, 7.03.

\section{(R)-5-[(Phenylmethoxy)methyl]-5-[(triphenylmethoxy)methyl]-3,4,5-trihydrofuran-}

\section{2-one (6).}

$\mathrm{BH}_{3} \bullet \mathrm{SMe}_{2}$ complex (2 $\mathrm{M}$ in THF, $2.5 \mathrm{~mL}$ ) was slowly added to a $-75^{\circ} \mathrm{C}$ solution of $\mathbf{5}$ (1.52 $\mathrm{g}, 3.3 \mathrm{mmol})$ in THF $(20 \mathrm{~mL})$. After stirring for $24 \mathrm{~h}$ at room temperature, the reaction mixture was concentrated in vacuo. The residue was then dissolved in $\mathrm{CH}_{2} \mathrm{Cl}_{2}$ $(40 \mathrm{~mL})$ and treated with pyridinium chlorochromate (PCC, $7.11 \mathrm{~g}, 33 \mathrm{mmol})$. After stirring for $24 \mathrm{~h}$, the mixture was quenched with $\mathrm{Et}_{2} \mathrm{O}$ and stirred for 30 additional min in the presence of Celite®. The resulting suspension was filtered through a short pad of silica gel and the filtrate collected was concentrated in vacuo. The residue was purified by flash column chromatography on silica gel with EtOAc/hexanes (1:4) as eluant to give 
6 as a white powder $(794 \mathrm{mg}, 48 \%), \mathrm{mp} 105-107^{\circ} \mathrm{C} ;[\alpha]_{\mathrm{D}}{ }^{23}=+10.15\left(c 2.1, \mathrm{CHCl}_{3}\right) ;{ }^{1} \mathrm{H}$ $\operatorname{NMR}\left(\mathrm{CDCl}_{3}\right) \delta$ 7.38-7.40 (m, $\left.5 \mathrm{H}, \mathrm{CH}_{2} \mathrm{OCH}_{2} \underline{\mathrm{Ph}}\right), 7.16-7.30\left(\mathrm{~m}, 15 \mathrm{H}, \mathrm{CH}_{2} \mathrm{OCPh}_{3}\right), 4.47$ (AB q, $\left.2 \mathrm{H}, J=12.0 \mathrm{~Hz}, \mathrm{CH}_{2} \mathrm{OC} \underline{\mathrm{H}}_{2} \mathrm{Ph}\right), 3.52\left(\mathrm{AB} \mathrm{q}, 2 \mathrm{H}, J=10.3 \mathrm{~Hz}, \mathrm{C}_{2} \mathrm{OCH}_{2} \mathrm{Ph}\right)$, $3.17\left(\mathrm{AB} \mathrm{q}, 2 \mathrm{H}, J=10.0 \mathrm{~Hz}, \mathrm{C}_{2} \mathrm{OCPh}_{3}\right), 2.48-2.62\left(\mathrm{~m}, 2 \mathrm{H}, \underline{\mathrm{H}}-3_{\mathrm{a}, \mathrm{b}}\right), 2.02-2.11(\mathrm{~m}, 1 \mathrm{H}$, $\underline{\mathrm{H}}-4_{\mathrm{a}}$ ), 1.90-1.98 (m, $\left.1 \mathrm{H}, \underline{\mathrm{H}}-4_{\mathrm{b}}\right)$; FABMS m/z (relative intensity) 517 (MK $\left.{ }^{+}, 43\right), 479$ $\left(\mathrm{MH}^{+}, 1\right), 243$ (100). Anal. Calcd for $\mathrm{C}_{32} \mathrm{H}_{30} \mathrm{O}_{4} \cdot 0.33 \mathrm{H}_{2} \mathrm{O}: \mathrm{C}, 79.32 ; \mathrm{H}, 6.37$. Found: $\mathrm{C}$, $79.11 ; \mathrm{H}, 6.35$.

(R)-3-(Z)-[5-Methyl-3-(2-methylpropyl)hexylidene]-5-[(phenylmethoxy)methyl]-5[(triphenylmethoxy)methyl]-4,5-dihydrofuran-2-one (Z)-7 and $(R)-3-(E)$-[5-Methyl-

\section{3-(2-methylpropyl)hexylidene]-5-[(phenylmethoxy)methyl]-5-} [(triphenylmethoxy)methyl]-4,5-dihydrofuran-2-one $(E)-7$.

A stirred solution of $(R)-6(1.5 \mathrm{~g}, 3.1 \mathrm{mmol})$ in THF $(10 \mathrm{~mL})$ was cooled to $-78{ }^{\circ} \mathrm{C}$ and treated dropwise with a solution of lithium bis(trimethylsilyl)amide (LHMDS, $1 \mathrm{M}$ in THF, $6.2 \mathrm{~mL}$ ). After $30 \mathrm{~min}$ at $-78{ }^{\circ} \mathrm{C}$, the mixture was treated with a solution of 5methyl-3-(2-methylpropyl)hexan-1-one $(527 \mathrm{mg}, 3.1 \mathrm{mmol})$ in THF $(10 \mathrm{~mL})$ and stirred for $1 \mathrm{~h}$ at the same temperature. The reaction was then quenched by slow addition of a saturated aqueous solution of $\mathrm{NH}_{4} \mathrm{Cl}$ and extracted with ether several times. The combined organic extracts were washed with water and brine, dried $\left(\mathrm{MgSO}_{4}\right)$ and concentrated in vacuo. The residue was purified by flash column chromatography on silica gel with EtOAc:hexanes (1:10) as eluant to give the intermediate aldol adduct as an 
oil $(2.0 \mathrm{~g}, 3.1 \mathrm{mmol})$. This intermediate was then taken up in $\mathrm{CH}_{2} \mathrm{Cl}_{2}(10 \mathrm{~mL})$, cooled to $0{ }^{\circ} \mathrm{C}$ and treated with triethylamine $(1.3 \mathrm{~mL}, 9.6 \mathrm{mmol})$ and methanesulfonyl chloride $(0.37 \mathrm{~mL}, 4.8 \mathrm{mmol})$. After stirring $5 \mathrm{~min}$ at room temperature, 1,8diazabicyclo[5.4.0]undec-7-ene (DBU, $1.4 \mathrm{~mL}, 9.6 \mathrm{mmol})$ was added and after $10 \mathrm{~min}$ the reaction mixture was concentrated in vacuo. The residue was purified by flash column chromatography on silica gel with EtOAc:hexanes (1:20) as eluant to give (Z)-7 (900 mg, $1.4 \mathrm{mmol}, 43 \%)$ and $(\boldsymbol{E})-7(800 \mathrm{mg}, 40 \%)$ as oils.

(Z)-7: $[\alpha]_{\mathrm{D}}^{22}=-2.8\left(\right.$ c 2.41, $\left.\mathrm{CHCl}_{3}\right) ;{ }^{1} \mathrm{H} \mathrm{NMR}\left(\mathrm{CDCl}_{3}\right) \delta$ 7.39-7.42 (m, $5 \mathrm{H}$, $\left.\mathrm{CH}_{2} \mathrm{OCH}_{2} \underline{\mathrm{Ph}}\right), 7.20-7.32\left(\mathrm{~m}, 15 \mathrm{H}, \mathrm{CH}_{2} \mathrm{OC}^{\mathrm{Ph}} 3\right), 6.11-6.15(\mathrm{~m}, 1 \mathrm{H},>\mathrm{C}=\mathrm{C} \underline{\mathrm{H}}), 4.52$ (s, 2 $\mathrm{H}, \mathrm{CH}_{2} \mathrm{OC}_{2} \mathrm{Ph}$ ), $3.59\left(\mathrm{AB} \mathrm{q}, 2 \mathrm{H}, J=10.4 \mathrm{~Hz}, \underline{\mathrm{C}}_{2} \mathrm{OCH}_{2} \mathrm{Ph}\right), 3.23(\mathrm{AB} \mathrm{q}, 2 \mathrm{H}, J=9.6$ $\left.\mathrm{Hz}, \underline{\mathrm{CH}}_{2} \mathrm{OTr}\right), 2.56-2.83\left(\mathrm{~m}, 4 \mathrm{H},>\mathrm{C}=\mathrm{CHC}_{2}{ }_{2} \mathrm{CH}\left(\mathrm{CH}_{2} \underline{\mathrm{HMe}}_{2}\right)_{2}\right.$ and $\left.\underline{\mathrm{H}}-4 \mathrm{ab}\right), 1.57-1.69$ (m, $\left.3 \mathrm{H},>\mathrm{C}=\mathrm{CHCH}_{2} \mathrm{CH}\left(\mathrm{CH}_{2} \underline{\mathrm{HMe}}_{2}\right)_{2}\right), 1.08$ (irr t, $4 \mathrm{H}, J=6.9 \mathrm{~Hz}$, $\left.>\mathrm{C}=\mathrm{CHCH}_{2} \mathrm{CH}\left(\mathrm{C}_{2} \mathrm{CHMe}_{2}\right)_{2}\right), 0.84-0.86\left(\mathrm{~m}, 12 \mathrm{H},>\mathrm{C}=\mathrm{CHCH}_{2} \mathrm{CH}\left(\mathrm{CH}_{2} \mathrm{CHMe}_{2}\right)_{2}\right) ;{ }^{13} \mathrm{C}$ $\operatorname{NMR}\left(\mathrm{CDCl}_{3}\right) \delta 169.5,143.7,143.1,138.0,128.8,128.5,128.0,127.8,127.7,127.3$, $125.7,87.0,83.3,73.7,72.4,65.8,44.1,34.3,33.5,32.1,25.3,23.2,23.2,22.9,22.8$; FABMS $m / z$ (relative intensity) $670\left(\mathrm{MK}^{+}, 10\right), 631\left(\mathrm{MH}^{+}, 1\right), 243(100)$. Anal. Calcd for $\mathrm{C}_{43} \mathrm{H}_{50} \mathrm{O}_{4} \cdot 0.2 \mathrm{H}_{2} \mathrm{O}: \mathrm{C}, 81.40 ; \mathrm{H}, 8.00$. Found: C, 81.07; H, 8.06.

(E)-7: $[\alpha]_{\mathrm{D}}^{22}=+14.1\left(c 1.95, \mathrm{CHCl}_{3}\right) ;{ }^{1} \mathrm{H} \mathrm{NMR}\left(\mathrm{CDCl}_{3}\right) \delta$ 7.39-7.42 (m, $5 \mathrm{H}$, $\left.\mathrm{CH}_{2} \mathrm{OCH}_{2} \underline{\mathrm{Ph}}\right), 7.19-7.33\left(\mathrm{~m}, 15 \mathrm{H}, \mathrm{CH}_{2} \mathrm{OCPh}_{3}\right), 6.75-6.79(\mathrm{~m}, 1 \mathrm{H}$, $\left.>\mathrm{C}=\mathrm{C}_{\underline{H C H}} \mathrm{CH}\left(\mathrm{CH}_{2} \mathrm{CHMe}_{2}\right)_{2}\right), 4.51\left(\mathrm{AB} \mathrm{q}, 2 \mathrm{H}, J=12.2 \mathrm{~Hz}, \mathrm{CH}_{2} \mathrm{OC}_{2} \mathrm{Ph}\right), 3.58(\mathrm{~s}, 2 \mathrm{H}$, $\mathrm{C}_{2} \mathrm{OCH}_{2} \mathrm{Ph}$ ), $3.25\left(\mathrm{AB} \mathrm{q}, 2 \mathrm{H}, J=9.7 \mathrm{~Hz}, \mathrm{CH}_{2} \mathrm{OCPh}_{3}\right), 2.58-2.74$ (m, 2H, H-4 ab), 2.08 (irr t, $\left.2 \mathrm{H},>\mathrm{C}=\mathrm{CHCH}_{2} \mathrm{CH}\left(\mathrm{CH}_{2} \mathrm{CHMe}_{2}\right)_{2}\right), 1.55-1.72(\mathrm{~m}, 3 \mathrm{H}$, 
$\left.>\mathrm{C}=\mathrm{CHCH}_{2} \mathrm{C} \underline{\mathrm{H}}\left(\mathrm{CH}_{2} \mathrm{CHMe}_{2}\right)_{2}\right), 1.04-1.10\left(\mathrm{~m}, 4 \mathrm{H},>\mathrm{C}=\mathrm{CHCH}_{2} \mathrm{CH}\left(\mathrm{C}_{2} \mathrm{CHMe}_{2}\right)_{2}\right), 0.82-$

$0.90\left(\mathrm{~m}, 12 \mathrm{H},>\mathrm{C}=\mathrm{CHCH}_{2} \mathrm{CH}\left(\mathrm{CH}_{2} \mathrm{CHMe}_{2}\right)_{2}\right) ;{ }^{13} \mathrm{C} \mathrm{NMR}\left(\mathrm{CDCl}_{3}\right) \delta 170.5,143.6,139.5$, $137.9,128.8,128.6,128.0,127.9,127.8,127.7,127.3,87.0,84.1,73.8,72.5,65.9,43.9$, $34.8,32.9,31.1,25.3,23.2,23.1,22.8,22.7$; FABMS $m / z$ (relative intensity) $631\left(\mathrm{MH}^{+}\right.$, 2), $669\left(\mathrm{MK}^{+}, 5\right), 243$ (100). Anal. Calcd for $\mathrm{C}_{43} \mathrm{H}_{50} \mathrm{O}_{4} \cdot 0.2 \mathrm{H}_{2} \mathrm{O}: \mathrm{C}, 81.40 ; \mathrm{H}, 8.00$.

Found: C, 81.12; H, 7.99.

(S)-5-(Hydroxymethyl)-3-(Z)-[5-methyl-3-(2-methylpropyl)hexylidene]-5[(phenylmethoxy)methyl]-4,5-dihydrofuran-2-one ((Z)-8).

Following the same method as above, $(Z)-7(876 \mathrm{mg}, 1.3 \mathrm{mmol})$ was deprotected to give (Z)-8 as an oil $(300 \mathrm{mg}, 60 \%) \cdot[\alpha]_{\mathrm{D}}^{22}=+4.90\left(c 1.69, \mathrm{CHCl}_{3}\right) ;{ }^{1} \mathrm{H} \mathrm{NMR}\left(\mathrm{CDCl}_{3}\right) \delta 7.27-$ 7.37 (m, $\left.5 \mathrm{H}, \mathrm{CH}_{2} \mathrm{OCH}_{2} \mathrm{Ph}\right), 6.20$ (tt, $1 \mathrm{H}, J=7.5,2.3 \mathrm{~Hz}$, $\left.>\mathrm{C}=\mathrm{C}_{\mathrm{HCH}} \mathrm{CH}\left(\mathrm{CH}_{2} \mathrm{CHMe}_{2}\right)_{2}\right), 4.56\left(\mathrm{AB} \mathrm{q}, 2 \mathrm{H}, J=12.3 \mathrm{~Hz}, \mathrm{CH}_{2} \mathrm{OC} \underline{H}_{2} \mathrm{Ph}\right), 3.74(\mathrm{dd}, 1$ $\mathrm{H}, J=12.1,7.0 \mathrm{~Hz}, \mathrm{C} \underline{\mathrm{HHOH}}), 3.67(\mathrm{dd}, 1 \mathrm{H}, J=12.1,6.3 \mathrm{~Hz}, \mathrm{CH} \underline{\mathrm{HOH}}), 3.56$ (AB q, 2 $\left.\mathrm{H}, J=10.0 \mathrm{~Hz}, \mathrm{C}_{2} \mathrm{OCH}_{2} \mathrm{Ph}\right), 2.81-2.83\left(\mathrm{~m}, 2 \mathrm{H}, \underline{\mathrm{H}}-4_{\mathrm{ab}}\right), 2.64-2.69(\mathrm{~m}, 2 \mathrm{H}$, $\left.>\mathrm{C}=\mathrm{CHCH}_{2} \mathrm{CH}\left(\mathrm{CH}_{2} \mathrm{CHMe}_{2}\right)_{2}\right), 2.11-2.14\left(\mathrm{~m}, 1 \mathrm{H}, \mathrm{CCH}_{2} \mathrm{OH}\right), 1.57-1.70(\mathrm{~m}, 3 \mathrm{H}, 2 \times$ $\left.>\mathrm{C}=\mathrm{CHCH}_{2} \mathrm{C} \underline{\mathrm{H}}\left(\mathrm{CH}_{2} \mathrm{CHMe}_{2}\right)_{2}\right), 1.07-1.12$ (irr t, $\left.4 \mathrm{H},>\mathrm{C}=\mathrm{CHCH}_{2} \mathrm{CH}\left(\mathrm{C}_{2} \mathrm{CHMe}_{2}\right)_{2}\right)$, $0.82-0.87\left(\mathrm{~m}, 12 \mathrm{H},>\mathrm{C}=\mathrm{CHCH}_{2} \mathrm{CH}\left(\mathrm{CH}_{2} \mathrm{CHMe}\right)_{2}\right) ;{ }^{13} \mathrm{C} \mathrm{NMR}\left(\mathrm{CDCl}_{3}\right) \delta 169.14,144.08$, $137.55,128.48,127.88,127.64,125.08,83.30,73.72,71.87,65.47,43.94,33.40,33.23$, 32.01, 25.13, 23.06, 22.68; FABMS m/z (relative intensity) $389\left(\mathrm{MH}^{+}, 31\right), 91$ (100). Anal. Calcd for $\mathrm{C}_{24} \mathrm{H}_{36} \mathrm{O}_{4}:$ C, 74.19; H, 9.34. Found: C, 74.01; H, 9.41.

(S)-5-(Hydroxymethyl)-3-(E)-[5-methyl-3-(2-methylpropyl)hexylidene]-5- 


\section{[(phenylmethoxy)methyl]-4,5-dihydrofuran-2-one ((E)-8).}

A solution of $(E)-7$ (776 mg, $1.2 \mathrm{mmol})$ in $\mathrm{CH}_{2} \mathrm{Cl}_{2}(4 \mathrm{~mL})$ was cooled to $0{ }^{\circ} \mathrm{C}$ and treated with formic acid $(1 \mathrm{ml})$. After stirring $24 \mathrm{~h}$ at room temperature, the reaction was quenched by slow addition of $\mathrm{NaHCO}_{3}$. The reaction mixture was then diluted with additional $\mathrm{CH}_{2} \mathrm{Cl}_{2}$, and the organic layer was washed with water and brine, dried $\left(\mathrm{MgSO}_{4}\right)$ and concentrated in vacuo. The residue was purified by flash column chromatography on silica gel with EtOAc:hexanes (1:2) as eluant to give (E)-8 as an oil (418 mg, $92 \%) .[\alpha]_{\mathrm{D}}^{22}=-9.57\left(c 0.96, \mathrm{CHCl}_{3}\right) ;{ }^{1} \mathrm{H} \mathrm{NMR}\left(\mathrm{CDCl}_{3}\right) \delta$ 7.26-7.37 (m, $5 \mathrm{H}$, $\left.\mathrm{CH}_{2} \mathrm{OCH}_{2} \underline{\mathrm{Ph}}\right), 6.73-6.79\left(\mathrm{~m}, 1 \mathrm{H},>\mathrm{C}=\mathrm{C}_{\underline{H}} \mathrm{H}_{2} \mathrm{CH}\left(\mathrm{CH}_{2} \mathrm{CHMe}_{2}\right)_{2}\right), 4.56(\mathrm{AB} \mathrm{q}, 2 \mathrm{H}, J=$ $12.7 \mathrm{~Hz}, \mathrm{CH}_{2} \mathrm{OCH}_{2} \mathrm{Ph}$ ), 3.77 (dd, $1 \mathrm{H}, J=12.1,7.0 \mathrm{~Hz}, \mathrm{C} \underline{\mathrm{HHOH}}$ ), 3.68 (dd, $J=6.5,12.2$ $\mathrm{Hz}, 1 \mathrm{H}, \mathrm{CH} \underline{\mathrm{HOH}}$ ), $3.58\left(\mathrm{AB} \mathrm{q}, 2 \mathrm{H}, J=10.0 \mathrm{~Hz}, \mathrm{C}_{2} \mathrm{OCH}_{2} \mathrm{Ph}\right.$ ), 2.67-2.79 (m, $2 \mathrm{H}, \underline{\mathrm{H}}-$ $4 \mathrm{ab}), 2.10-2.13\left(\mathrm{~m}, 2 \mathrm{H},>\mathrm{C}=\mathrm{CHCH}_{2} \mathrm{CH}\left(\mathrm{CH}_{2} \mathrm{CHMe}_{2}\right)_{2}\right), 1.58-1.73(\mathrm{~m}, 3 \mathrm{H}$, $\left.>\mathrm{C}=\mathrm{CHCH}_{2} \mathrm{C} \underline{\mathrm{H}}\left(\mathrm{CH}_{2} \mathrm{CHMe}_{2}\right)_{2}\right), 1.07-1.11\left(\mathrm{~m}, 4 \mathrm{H},>\mathrm{C}=\mathrm{CHCH}_{2} \mathrm{CH}\left(\mathrm{C}_{2} \mathrm{CHMe}_{2}\right)_{2}\right), 0.87$ and $0.85\left(\mathrm{~s}, 12 \mathrm{H},>\mathrm{C}=\mathrm{CHCH}_{2} \mathrm{CH}\left(\mathrm{CH}_{2} \mathrm{CHMe}_{2}\right)_{2}\right) ;{ }^{13} \mathrm{C} \mathrm{NMR}\left(\mathrm{CDCl}_{3}\right) \delta$ 170.37, 140.70, 137.70, 128.69, 128.10, $127.84,127.41,84.29,73.95,72.15,65.79,44.04,34.91,33.00$, 30.37, 25.41, 23.16, 22.81; FABMS m/z (relative intensity) $389\left(\mathrm{MH}^{+}, 38\right), 91$ (100). Anal. Calcd for $\mathrm{C}_{24} \mathrm{H}_{36} \mathrm{O}_{4} \cdot 0.2 \mathrm{H}_{2} \mathrm{O}$ : C, 73.50; H, 9.25. Found: C, 73.50; H, 9.27.

\section{(R)-\{4-(Z)-[5-Methyl-3-(2-methylpropyl)hexylidene]-5-oxo-2-}

[(phenylmethoxy)methyl]-2-2,3-dihydrofuryl $\}$ methyl 2,2-Dimethylpropanoate $((Z)$ 9).

Following the same method as above, $(Z)-8(271 \mathrm{mg}, 0.69 \mathrm{mmol})$ was acylated to give (Z)-9 as an oil $(326 \mathrm{mg}, 100 \%) \cdot[\alpha]_{\mathrm{D}}{ }^{22}=+6.42\left(c 1.51, \mathrm{CHCl}_{3}\right) ;{ }^{1} \mathrm{H} \mathrm{NMR}\left(\mathrm{CDCl}_{3}\right) \delta$ 
7.27-7.37 (m, $\left.5 \mathrm{H}, \mathrm{CH}_{2} \mathrm{OCH}_{2} \underline{\mathrm{Ph}}\right), 6.21(\mathrm{tt}, 1 \mathrm{H}, J=7.5,2.3 \mathrm{~Hz}$, $\left.>\mathrm{C}=\mathrm{CHCH}_{2} \mathrm{CH}\left(\mathrm{CH}_{2} \mathrm{CHMe}_{2}\right)_{2}\right), 4.57\left(\mathrm{~s}, 2 \mathrm{H}, \mathrm{CH}_{2} \mathrm{OCH}_{2} \mathrm{Ph}\right), 4.20(\mathrm{AB} \mathrm{q}, 2 \mathrm{H}, J=11.8$, $\left.\mathrm{Hz}, \underline{\mathrm{C}}_{2} \mathrm{OC}(\mathrm{O}) \mathrm{CMe}_{3}\right), 3.55\left(\mathrm{AB} \mathrm{q}, 2 \mathrm{H}, J=10.0 \mathrm{~Hz}, \underline{\mathrm{C}}_{2} \mathrm{OCH}_{2} \mathrm{Ph}\right), 2.90$ (dq, $\left.1 \mathrm{H}, \underline{\mathrm{H}}-4_{\mathrm{a}}\right)$, 2.60-2.80 (m, $3 \mathrm{H},>\mathrm{C}=\mathrm{CHCH}_{2} \mathrm{CH}\left(\mathrm{CH}_{2} \mathrm{C}_{1} \mathrm{He}_{2}\right)_{2}$ and $\left.\underline{\mathrm{H}}-4_{\mathrm{b}}\right), 1.57-1.70(\mathrm{~m}, 3 \mathrm{H}$, $\left.>\mathrm{C}=\mathrm{CHC} \underline{H}_{2} \mathrm{C} \underline{\mathrm{H}}\left(\mathrm{CH}_{2} \mathrm{CHMe}_{2}\right)_{2}\right), 1.17\left(\mathrm{~s}, 9 \mathrm{H}, \mathrm{CCH}_{2} \mathrm{OC}(\mathrm{O}) \underline{\mathrm{CMe}}_{3}\right), 1.07-1.11$ (irr tt, $4 \mathrm{H}$, $\left.>\mathrm{C}=\mathrm{CHCH}_{2} \mathrm{CH}\left(\mathrm{CH}_{2} \mathrm{CHMe}_{2}\right)_{2}\right), 0.84-0.88\left(\mathrm{dm}, 12 \mathrm{H},>\mathrm{C}=\mathrm{CHCH}_{2} \mathrm{CH}\left(\mathrm{CH}_{2} \mathrm{CHMe}_{2}\right)_{2}\right) ;{ }^{13} \mathrm{C}$ $\operatorname{NMR}\left(\mathrm{CDCl}_{3}\right) \delta 170.20,168.71,143.79,137.42,128.48,127.90,127.66,124.79,81.46$ $73.74,71.83,65.98,43.91,38.90,33.85,33.21,32.03,27.09,25.14,25.11,23.02,22.68$; FABMS $m / z$ (relative intensity) $473\left(\mathrm{MH}^{+}, 31\right), 91$ (100). Anal. Calcd for $\mathrm{C}_{29} \mathrm{H}_{44} \mathrm{O}_{5}: \mathrm{C}$, 73.69; H, 9.38. Found: C, 73.39; H, 9.25.

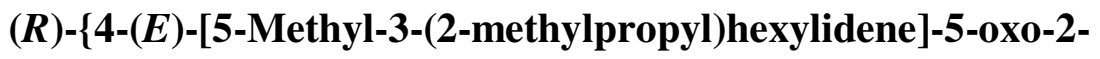
[(phenylmethoxy)methyl]-2-2,3-dihydrofuryl\}methyl 2,2-Dimethylpropanoate ((E)9). A solution of (E)-8 (396 mg, $1.0 \mathrm{mmol})$ in $\mathrm{CH}_{2} \mathrm{Cl}_{2}(8 \mathrm{~mL})$ was treated with triethylamine $(0.4 \mathrm{~mL}, 3.0 \mathrm{mmol})$, pivaloyl chloride $(0.12 \mathrm{ml}, 1.5 \mathrm{mmol})$ and a catalytic amount of DMAP, and stirred at room temperature for $1 \mathrm{~h}$. The reaction mixture was then concentrated in vacuo and the residue was purified by flash column chromatography on silica gel with EtOAc:hexanes (1:10) as eluant to give (E)-9 as an oil (472 mg, 100 $\%) .[\alpha]_{\mathrm{D}}{ }^{22}=+7.80\left(c 2.01, \mathrm{CHCl}_{3}\right) ;{ }^{1} \mathrm{H} \mathrm{NMR}\left(\mathrm{CDCl}_{3}\right) \delta 7.27-7.37(\mathrm{~m}, 5 \mathrm{H}$, $\left.\mathrm{CH}_{2} \mathrm{OCH}_{2} \underline{\mathrm{Ph}}\right), 6.75-6.79\left(\mathrm{~m}, 1 \mathrm{H},>\mathrm{C}=\mathrm{C}_{\mathrm{HCH}} \mathrm{CH}\left(\mathrm{CH}_{2} \mathrm{CHMe}_{2}\right)_{2}\right), 4.57(\mathrm{~s}, 2 \mathrm{H}$, $\mathrm{CH}_{2} \mathrm{OCH}_{2} \mathrm{Ph}$ ), $4.22\left(\mathrm{AB} \mathrm{q}, 2 \mathrm{H}, J=11.8, \mathrm{~Hz}, \mathrm{C}_{2} \mathrm{OC}(\mathrm{O}) \mathrm{CMe}_{3}\right), 3.56(\mathrm{AB} \mathrm{q}, 2 \mathrm{H}, J=$ $\left.10.0 \mathrm{~Hz}, \underline{\mathrm{C}}_{2} \mathrm{OCH}_{2} \mathrm{Ph}\right), 2.82\left(\mathrm{dm}, 2 \mathrm{H}, \mathrm{J}=17.1 \mathrm{~Hz}, \underline{\mathrm{H}}-4_{\mathrm{a}}\right), 2.67(\mathrm{dm}, 2 \mathrm{H}, \mathrm{J}=17.1 \mathrm{~Hz}, \underline{\mathrm{H}}-$ 4b), 1.70 (irr pentet, $\left.1 \mathrm{H},>\mathrm{C}=\mathrm{CHCH}_{2} \mathrm{C} \underline{\mathrm{H}}\left(\mathrm{CH}_{2} \mathrm{CHMe}_{2}\right)_{2}\right), 1.62$ (irr sextet, $2 \mathrm{H}$, 
$\left.>\mathrm{C}=\mathrm{CHCH}_{2} \mathrm{CH}\left(\mathrm{CH}_{2} \mathrm{CHMe}_{2}\right)_{2}\right), 1.16\left(\mathrm{~s}, 9 \mathrm{H}, \mathrm{CCH}_{2} \mathrm{OC}(\mathrm{O}) \mathrm{CMe}_{3}\right), 1.05-1.13(\mathrm{~m}, 4 \mathrm{H}$, $\left.>\mathrm{C}=\mathrm{CHCH}_{2} \mathrm{CH}\left(\mathrm{CH}_{2} \mathrm{CHMe}_{2}\right)_{2}\right), 0.86(\mathrm{~d}, 12 \mathrm{H}, J=6.5 \mathrm{~Hz}$, $\left.>\mathrm{C}=\mathrm{CHCH}_{2} \mathrm{CH}\left(\mathrm{CH}_{2} \mathrm{CHMe}\right)_{2}\right) ;{ }^{13} \mathrm{C} \mathrm{NMR}\left(\mathrm{CDCl}_{3}\right) \delta 177.81,169.69,140.16,137.33$, $128.48,127.93,127.66,126.95,82.16,73.77,71.88,66.03,43.84,38.90,34.77,32.79$, 30.71, 27.07, 25.19, 22.94, 22.65; FABMS m/z (relative intensity) $473\left(\mathrm{MH}^{+}, 62\right), 91$ (100). Anal. Calcd for $\mathrm{C}_{29} \mathrm{H}_{44} \mathrm{O}_{5}$ : C, 73.69; H, 9.38. Found: C, 73.49; H, 9.22.

(R)-\{2-(Hydroxymethyl)-4-(Z)-[5-methyl-3-(2-methylpropyl)hexylidene]-5-oxo-2-2,3dihydrofuryl\}methyl 2,2-Dimethylpropanoate ((Z)-10).

Following the same method as above, $(Z)-9(300 \mathrm{mg}, 0.63 \mathrm{mmol})$ was acylated to give (Z)-10 as a white solid $(200 \mathrm{mg}, 82 \%)$. mp $44-45{ }^{\circ} \mathrm{C} ;[\alpha]_{\mathrm{D}}{ }^{23}=+7.23\left(c 0.65, \mathrm{CHCl}_{3}\right) ;{ }^{1} \mathrm{H}$ $\operatorname{NMR}\left(\mathrm{CDCl}_{3}\right) \delta$ 6.22-6.27 (m, $\left.1 \mathrm{H},>\mathrm{C}=\mathrm{CHCH}_{2} \mathrm{CH}\left(\mathrm{CH}_{2} \mathrm{CHMe}_{2}\right)_{2}\right), 4.20(\mathrm{AB} \mathrm{q}, 2 \mathrm{H}, J=$ $\left.11.8 \mathrm{~Hz}, \mathrm{C}_{2} \mathrm{OC}(\mathrm{O}) \mathrm{CMe}_{3}\right), 3.66\left(\mathrm{AB} \mathrm{q}, 2 \mathrm{H}, J=12.1 \mathrm{~Hz}, \underline{\mathrm{C}}_{2} \mathrm{OH}\right), 2.92(\mathrm{dm}, 1 \mathrm{H}, J=$ 16.6 Hz, $\left.\underline{\mathrm{H}}-4_{\mathrm{a}}\right), 2.59-2.74\left(\mathrm{~m}, 4 \mathrm{H},>\mathrm{C}=\mathrm{CHC} \underline{H}_{2} \mathrm{CH}\left(\mathrm{CH}_{2} \mathrm{CHMe}_{2}\right)_{2}, \mathrm{CCH}_{2} \mathrm{O} \underline{\mathrm{H}}\right.$ and $\left.\underline{\mathrm{H}}-4_{\mathrm{b}}\right)$, 1.57-1.69 (m, $\left.3 \mathrm{H},>\mathrm{C}=\mathrm{CHCH}_{2} \mathrm{C} \underline{\mathrm{H}}\left(\mathrm{CH}_{2} \underline{\mathrm{CHMe}}_{2}\right)_{2}\right), 1.19\left(\mathrm{~s}, 9 \mathrm{H}, \mathrm{C}_{2} \mathrm{OC}(\mathrm{O}) \mathrm{CMe}_{3}\right), 1.07-$ 1.10 (irr tt, $\left.4 \mathrm{H},>\mathrm{C}=\mathrm{CHC} \underline{H}_{2} \mathrm{CH}\left(\mathrm{CH}_{2} \mathrm{CHMe}_{2}\right)_{2}\right), 0.84-0.86(\mathrm{dm}, 12 \mathrm{H}, J=6.6 \mathrm{~Hz}$, $\left.>\mathrm{C}=\mathrm{CHCH}_{2} \mathrm{CH}\left(\mathrm{CH}_{2} \mathrm{CHMe}\right)_{2}\right) ;{ }^{13} \mathrm{C} \mathrm{NMR}\left(\mathrm{CDCl}_{3}\right) \delta 178.28,168.88,144.50,124.67$, $98.41,82.54,65.48,64.68,43.96,43.90,38.94,33.20,33.05,32.11,27.09,25.13,25.10$, 22.99, 22.68; FABMS m/z (relative intensity) $383\left(\mathrm{MH}^{+}, 18\right), 57$ (100). Anal. Calcd for $\mathrm{C}_{29} \mathrm{H}_{38} \mathrm{O}_{5} \cdot 0.2 \mathrm{H}_{2} \mathrm{O}: \mathrm{C}, 68.43 ; \mathrm{H}, 10.02$. Found: $\mathrm{C}, 68.71 ; \mathrm{H}, 10.07$.

(R)-\{2-(Hydroxymethyl)-4-(E)-[5-methyl-3-(2-methylpropyl)hexylidene]-5-oxo-2-2,3dihydrofuryl\}methyl 2,2-Dimethylpropanoate ((E)-10). 
A stirred solution of $(E)-9(450 \mathrm{mg}, 0.95 \mathrm{mmol})$ in $\mathrm{CH}_{2} \mathrm{Cl}_{2}(5 \mathrm{~mL})$ was cooled to $-78{ }^{\circ} \mathrm{C}$ and treated dropwise with $\mathrm{BCl}_{3}\left(1 \mathrm{M}\right.$ soln in $\left.\mathrm{CH}_{2} \mathrm{Cl}_{2}, 2.9 \mathrm{~mL}\right)$. After $1 \mathrm{~h}$ at $-78{ }^{\circ} \mathrm{C}$ the reaction was quenched with a saturated aqueous $\mathrm{NaHCO}_{3}$ and immediately partitioned between ether and water. The organic layer was washed with water and brine, dried $\left(\mathrm{MgSO}_{4}\right)$ and concentrated in vacuo. The residue was purified by flash column chromatography on silica gel with EtOAc:hexanes (1:4) as eluant to give $(E)-\mathbf{1 0}$ as an oil $(286 \mathrm{mg}, 79 \%) \cdot[\alpha]_{\mathrm{D}}{ }^{23}=+17.54\left(c 2.16, \mathrm{CHCl}_{3}\right) ;{ }^{1} \mathrm{H} \mathrm{NMR}\left(\mathrm{CDCl}_{3}\right) \delta$ 6.73-6.78 (m, $1 \mathrm{H}$, $\left.>\mathrm{C}=\mathrm{C}_{\underline{H C}} \mathrm{H}_{2} \mathrm{CH}\left(\mathrm{CH}_{2} \mathrm{CHMe}_{2}\right)_{2}\right), 4.20\left(\mathrm{AB} \mathrm{q}, 2 \mathrm{H}, J=11.8 \mathrm{~Hz}, \underline{\mathrm{C}}_{2} \mathrm{OC}(\mathrm{O}) \mathrm{CMe}_{3}\right), 3.67$

$\left(\mathrm{AB} \mathrm{q}, 2 \mathrm{H}, J=11.3 \mathrm{~Hz}, \underline{\mathrm{C}}_{2} \mathrm{OH}\right), 2.92$ (br s, $1 \mathrm{H}, \mathrm{CH}_{2} \mathrm{OH}$ ), 2.83 (dm, $1 \mathrm{H}, J=17.1 \mathrm{~Hz}$, $\left.\underline{\mathrm{H}}-4_{\mathrm{a}}\right), 2.64\left(\mathrm{dm}, 1 \mathrm{H}, J=17.1 \mathrm{~Hz}, \underline{\mathrm{H}}-4_{\mathrm{b}}\right), 2.09-2.12(\mathrm{~m}, 2 \mathrm{H}$, $\left.>\mathrm{C}=\mathrm{CHCH}_{2} \mathrm{CH}\left(\mathrm{CH}_{2} \mathrm{CHMe}_{2}\right)_{2}\right), 1.69$ (pentet, $1 \mathrm{H}, J=6.6 \mathrm{~Hz}$, $\left.>\mathrm{C}=\mathrm{CHCH}_{2} \mathrm{CH}\left(\mathrm{CH}_{2} \mathrm{CHMe}_{2}\right)_{2}\right), 1.69$ (septet, $2 \mathrm{H}, J=6.6 \mathrm{~Hz}$, $\left.>\mathrm{C}=\mathrm{CHCH}_{2} \mathrm{CH}\left(\mathrm{CH}_{2} \underline{\mathrm{CHMe}}_{2}\right)_{2}\right), 1.16\left(\mathrm{~s}, 9 \mathrm{H}, \mathrm{CH}_{2} \mathrm{OC}(\mathrm{O}) \underline{\mathrm{CMe}}_{3}\right), 1.05-1.13(\mathrm{~m}, 4 \mathrm{H}$, $\left.>\mathrm{C}=\mathrm{CHCH}_{2} \mathrm{CH}\left(\mathrm{C}_{2} \mathrm{CHMe}_{2}\right)\right), 0.85(\mathrm{dd}, 12 \mathrm{H}, J=6.6,1.2 \mathrm{~Hz}$, $\left.>\mathrm{C}=\mathrm{CHCH}_{2} \mathrm{CH}\left(\mathrm{CH}_{2} \mathrm{CHMe}_{2}\right)_{2}\right) ;{ }^{13} \mathrm{C} \mathrm{NMR}\left(\mathrm{CDCl}_{3}\right) \delta 178.20,169.99,140.76,126.94$, $83.41,65.61,64.74,43.83,38.92,34.82,32.76,29.90,27.05,25.19,25.16,22.91,22.61$; FABMS $m / z$ (relative intensity) $383\left(\mathrm{MH}^{+}, 26\right), 57$ (100). Anal. Calcd for $\mathrm{C}_{29} \mathrm{H}_{38} \mathrm{O}_{5} \cdot 0.2 \mathrm{H}_{2} \mathrm{O}: \mathrm{C}, 68.43 ; \mathrm{H}, 10.02$. Found: C, 68.71; H, 10.01. 


\section{$\underline{\text { References }}$}

(1) Lewin, N. E.; Blumberg, P. M. Methods Mol. Biol. 2003, 233, 129-156. 